\title{
XÂY DỰNG KỊCH BẢN BIẾN ĐỔI LƯợNG MƯA TẠI KHU VỰC TỈNH TÂY NINH TRONG BỐI CẢNH BIẾN ĐỔI KHÍ HậU
}

\author{
Lê Ngọc Tuấn ${ }^{1 *}$, Nguyễn Văn Tín ${ }^{2}$, \\ Trần Tuấn Hoàng ${ }^{2}$, Phạm Thanh Long ${ }^{2}$, Nguyễn Kỳ Phùng ${ }^{3}$
}

Tóm tắt: Bằng phần mềm SimCLIM, nghiên cứu đã xây dụng các kịch bản biến đổi lượng mưa tại tỉnh Tây Ninh đến năm 2100. Theo thời gian cũng nhu theo các kịch bản RCPs (RCP2.6 RCP8.5), lương mưa năm có xu hướng gia tăng: 18-20\% RCP4.5 và 22-26\% RCP8.5 vào năm 2100 so với giai đoạn 1986-2005. Số liệu tương úng với lương mua mùa mura là 16-20\% và 21-26\%. Theo không gian, lượng mura (theo năm và theo mùa) phân bố giảm dần tì̀ Tây sang Đông. Đối với kịch bản RCP4.5, lương muxa mùa mura năm 2050 dao động tù̀ 1200-1900 mm, cao nhất ở Huyện Châu Thành, Tân Biên (1800-1900mm), sau là Tp. Tây Ninh, Gò Dà̀u, Trảng Bàng (1500-1600mm) và thấp nhất tại Dưong Minh Châu (1200-1300mm). Kết quả nghiên cưu là cơ sỏ quan trọng phục vu đánh giá tác động, đánh giá tính dễ bị tổn thương do sụ thay đổi lượng mưa nói riêng và BĐKH nói chung tại địa phưong.

Từ khóa: Biến đổi lượng mưa, lương mưa năm, lựng mưa mùa mưa, kịch bản BĐKH.

Ban Biên tập nhận bài: 12/10/2019 Ngày phản biện xong: 26/11/2019 Ngày đăng bài: 25/01/2020

\section{1. Đặt vấn đề}

Biến đổi khí hậu $(\mathrm{BĐKH})$ biểu hiện bởi sự nóng lên toàn cầu, mực nước biển dâng (NBD) và gia tăng các hiện tượng khí tượng thủy văn cực đoan [1], đã và đang tác động trực tiếp đến đời sống kinh tế - xã hội $(\mathrm{KTXH})$ và môi trường toàn cầu. Nghiên cứu về $\mathrm{BĐKH}$ theo đó rất được quan tâm và có thể chia thành ba nhóm lớn: (N1) Bản chất, nguyên nhân, cơ chế vật lý của sự BĐKH; (N2) Đánh giá tác động của BĐKH, tính DBTT do $B Đ K H$ và giải pháp thích ứng; (N3) Giải pháp, chiến lược và kế hoạch hành động nhằm giảm thiểu $\mathrm{BĐKH} \mathrm{[2].} \mathrm{Về} \mathrm{logic,} \mathrm{nghiên}$ cứu $\mathrm{BĐKH} \mathrm{cần} \mathrm{được} \mathrm{thực} \mathrm{hiện} \mathrm{tuần} \mathrm{tự,} \mathrm{trong} \mathrm{đó}$ nhóm (N1) cần tiến hành đầu tiên với hai nhóm chính: (i) Xác định các bằng chứng, nguyên nhân gây BĐKH trong quá khứ và hiện tại; (ii) Đánh

${ }^{1}$ Truò̀ng Đại học Khoa học Tụ nhiên - Đại học Quốc gia Thành phố Hồ Chi Minh

2Phân viện Khoa học Khí tượng Thủy văn và Biến đổi Khi hậu

${ }^{3}$ Sỏ Khoa hoc và Công nghệ thành phố Hồ Chí Minh Email:Intuan@hcmus.edu.vn giá $\mathrm{BĐKH} \mathrm{trong} \mathrm{tương} \mathrm{lai} \mathrm{bao} \mathrm{gồm} \mathrm{việc} \mathrm{xây}$ dựng các kịch bản BĐKH.

Kịch bản BĐKH là giả định có cơ sở khoa học và tính tin cậy về sự tiến triển trong tương lai của các mối quan hệ giữa KTXH, GDP, phát thải KNK, BĐKH và mực NBD [1]. Đến nay, Ủy ban Liên chính phủ về BĐKH (IPCC) đã thực hiện 5 lần xây dựng và cập nhật kịch bản $\mathrm{BĐKH}$ thông qua các lần báo cáo đánh giá $\mathrm{BĐKH}$. Trong đó, sự thay đổi cơ bản của IPCC-AR5 liên quan đến các kịch bản phát thải KNK: RCPs (Representative Concentration Pathways) được sử dụng để dự đoán khí hậu trái đất đến năm 2100, gồm RCP2.6, RCP4.5, RCP6.0 và RCP8.5 tương ứng với nồng độ $\mathrm{KNK}$ quy đổi thành khí $\mathrm{CO}_{2}$ là $490 \mathrm{ppm}, 650$ ppm, 850 ppm và 1370 ppm [1].

Các phương pháp áp dụng trong xây dựng kịch bản BĐKH bao gồm 2 phương pháp chính: (i) Phương pháp thống kê; (ii) Phương pháp mô hình động lực. Phương pháp thống kê đã phát triển tương đối sớm, như dự báo mưa gió mùa (Monsoon rainfall) vào cuối thế kỷ 19, hay biến 


\section{BÀI BÁO KHOA HỌC}

động các hình thế khí áp trong vùng nhiệt đới [34]. Đến nay, nhiều mô hình thực nghiệm dự báo mùa với các phương pháp khác nhau đã được nghiên cứu và phát triển [5-9]. Thống kê là công cư ứng dụng khá phổ biến, có thể chia thành 3 nhóm [10]: Thống kê truyền thống; Hạ thấp quy mô thống kê (Chi tiết hóa thống kê) (Statistical Downscaling - SD); Thống kê trên sản phẩm mô hình (Model Output Statistics - MOS). Các mô hình khí hậu toàn cầu (GCM - Global Climate Model) và khu vực (RCM - Regional Climate Model) phát triển từ cuối những năm 1980. GCM là một mô hình toán học về tuần hoàn tổng quát của bầu khí quyển trái đất hoặc đại dương dựa trên các công thức toán mô tả các quá trình vật lý - là cơ sở cho những chương trình máy tính phức tạp thường được sử dụng để mô phỏng bầu khí quyển và các đại dương trên trái đất [11-13]. Úng dụng quan trọng nhất của các GCM nói chung là dự tính khí hậu tương lai (thế kỷ 21) dựa trên các kịch bản phát thải khí nhà kính là cơ sở để xây dựng các kịch bản BĐKH [14].

Tỉnh Tây Ninh thuộc miền Đông Nam Bộ, nằm trong vùng kinh tế trọng điểm phía Nam, là một trong những địa phương có tốc độ tăng trưởng kinh tế cao, phát triển công nghiệp năng động của cả nước. Kịch bản BĐKH tỉnh Tây Ninh [15] được xây dựng trên cơ sở kịch bản $\mathrm{BĐKH}$ và NBD cho Việt Nam (2009) [16] nhìn chung hỗ trợ tích cực cho công tác ứng phó $\mathrm{BĐKH}$ trên địa bàn. Tuy nhiên, với những thay đổi trong thời gian gần đây, cần thiết cập nhật số liệu khí tượng thủy văn (KTTV) tại địa phương cũng như kỹ thuật mô phỏng kịch bản BĐKH. Bằng phương pháp chi tiết hóa thống kê thông qua phần mềm SimCLIM, nghiên cứu nhằm mục tiêu xây dựng kịch bản biến đổi lượng mưa (năm, mùa) khu vực tỉnh Tây Ninh (theo các RCPs) đến năm 2100, thời kỳ so sánh 1986-2005 và chuỗi số liệu KTTV cập nhật đến năm 2017 , tạo cơ sở quan trọng để đánh giá tác động, đánh giá tính $\mathrm{DBTT}$ do $\mathrm{BĐKH}$, từ đó đề xuất các giải pháp ứng phó tương thích. SimCLIM là hệ thống phần mềm được phát triển bởi Viện Quốc tế về BĐKH toàn cầu, thuộc Đại học Waikato Newzealand, tích hợp các kết quả đầu ra của 40 GCMs mô phỏng các yếu tố khí tượng và 24 GCMs mô phỏng sự thay đổi của NBD, được ứng dụng thành công tại khu vực miền Trung [17] và miền Nam Việt Nam [18-20]. Do hạn chế của phần mềm SimCLIM, kịch bản lượng mưa cực trị gồm lượng mưa 01 ngày lớn nhất trung bình, lượng mưa 05 ngày lớn nhất trung bình không thuộc phạm vi của nghiên cứu này.

\section{Phương pháp nghiên cứu}

Sơ đồ phương pháp xây dựng kịch bản $\mathrm{BĐKH}$ được trình bày ở hình 1 .

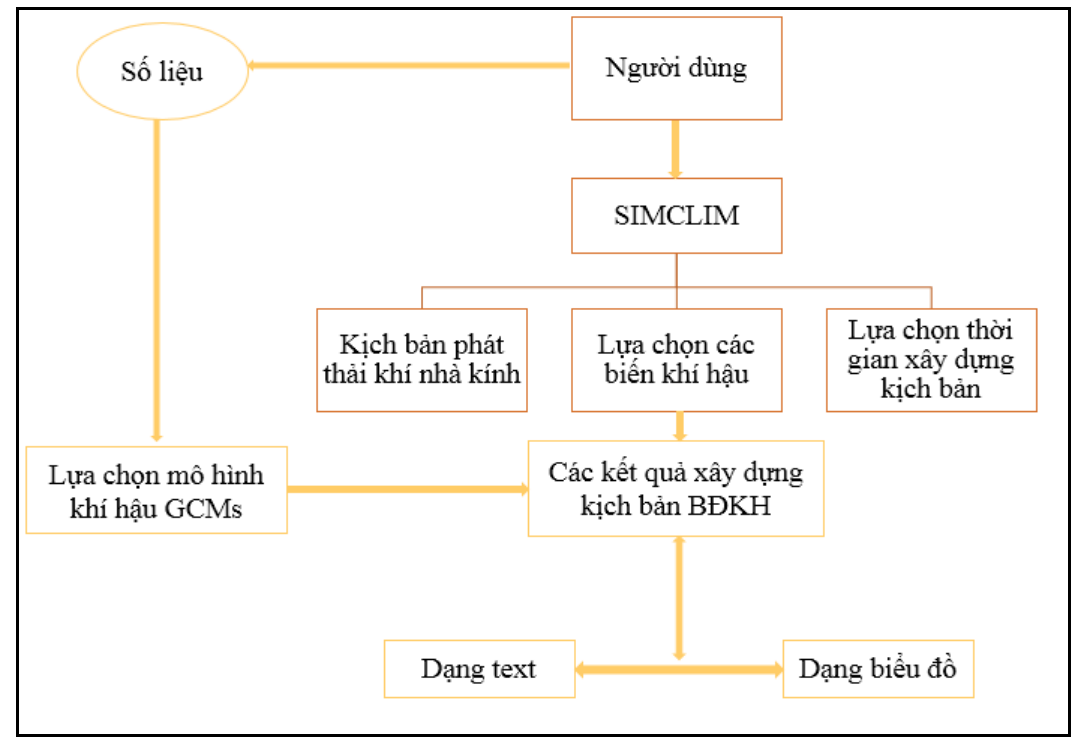

Hình 1. So đồ phương pháp xây dụng kịch bản BĐKH 
Trong nghiên cứu này, phần mền SimClim phiên bản DATAAR5REGIONAL - Downscaled spatial area for SimCLIM 2013 AR5 for South Vietnam được sử dụng. Từ kết quả của các mô hình GCMs tích hợp sẵn trong phần mềm, thực hiện chi tiết hoá (Statistical Downscaling) đến khu vực tỉnh Tây Ninh với độ phân giải $1 \mathrm{~km}$.

Dữ liệu lượng mưa ngày tại các trạm quan trắc Kà Tum, Núi Bà, Bến Sỏi, Tây Ninh, Gò Dầu Hạ, Cần Đăng giai đoạn 1986-2017, Đồng Ban, Đồi 95 giai đoạn 1989-2017 và hồ Dầu Tiếng giai đoạn 1993-2017 được thu thập (từ Đài Khí tượng Thủy văn khu vực Nam Bộ) nhằm mô tả điều kiện cụ thể của địa phương, đồng thời so sánh,

$$
\mathrm{RE}(\mathrm{R})=\frac{1}{\mathrm{~N}} \sum_{\mathrm{i}=1}^{\mathrm{N}}\left(\frac{\left(\mathrm{R}_{\mathrm{fi}}-\mathrm{R}_{\mathrm{oi}}\right) * 100}{\mathrm{R}_{\mathrm{oi}}}\right) ; \operatorname{MARE}(\mathrm{R})=\frac{1}{\mathrm{~N}} \sum_{\mathrm{i}=1}^{\mathrm{N}}\left|\frac{\left(\mathrm{R}_{\mathrm{fi}}-\mathrm{R}_{\mathrm{oi}}\right) * 100}{\mathrm{R}_{\mathrm{oi}}}\right|
$$

Trong đó $\mathrm{R}_{\mathrm{f}}, \mathrm{R}_{\mathrm{o}}$ là tổng lượng mưa trạm cho một giai đoạn hoặc trung bình tổng lượng mưa trạm cho một giai đoạn trong khu vực mô phỏng và quan trắc. RE mang giá trị âm chỉ ra kết quả tính toán thấp hơn giá trị quan trắc và ngược lại. Bên cạnh đó, mô hình có kết quả hoàn hảo khi $\mathrm{MARE}=0$. MARE càng lớn, độ chính xác của mô hình càng kém.

Với 40 GCMs tích hợp trong SIMCLIM, 11 mô hình điển hình phù hợp với Việt Nam được lựa chọn để tính toán: ACCESS1-3 (Úc), CCSM4 (Mỹ), CMCC-CMS (Ý), CNRM-CM5 (Pháp), CSIRO-Mk3-6-0 (Úc), GFDL-CM3

Bảng 1. Sai số tương đối (RE) và tuyệt đối (MARE) của lựng mura (\%) giũa kết quả mô phỏng và thực đo tại khu vục tỉnh Tây Ninh giai đoạn 1986-2005

\begin{tabular}{ccccccc}
\hline \multirow{2}{*}{ Trạm } & \multicolumn{3}{c}{ RE (\%) } & \multicolumn{3}{c}{ MARE (\%) } \\
\cline { 2 - 7 } & Mùa khô & Mùa mưa & Năm & Mùa khô & Mùa mưa & Năm \\
\hline Cần Đăng & 31.8 & -13.5 & -5.9 & 59.1 & 17.0 & 14.0 \\
Gò Dầu Hạ & 61.0 & -2.1 & 6.9 & 65.1 & 17.9 & 14.3 \\
Dầu Tiếng & 38.7 & 1.9 & 8.9 & 57.8 & 12.4 & 18.3 \\
Tây Ninh & 33.2 & -14.7 & -6.5 & 59.6 & 23.0 & 18.7 \\
Trung bình & 41.2 & -7.1 & 0.9 & 60.4 & 17.6 & 16.3 \\
\hline
\end{tabular}

Có thể thấy sai số tương đối RE không đáng kể giữa kết quả mô phỏng lượng mưa năm trung bình toàn tỉnh so với số liệu thực đo $\left(\mathrm{RE}_{\text {tỉnh }}=\right.$ $0,9 \%)$. Trong đó, kết quả mô phỏng cao hơn thực đo tại trạm Gò Dầu Hạ $(6,9 \%)$ và Dầu Tiếng
(Mỹ), HADCM3 (UK), HadGEM2-AO (UK), MPI-ESM-LR (Đức), MRI-CGCM3 (Nhật) và NorESM1-M (Na Uy). Các mô hình này thuộc các trung tâm nghiên cứu khí hậu lớn trên thế giới được Bộ Tài nguyên và Môi trường sử dụng làm đầu vào cho các RCMs khi xây dựng kịch bản BĐKH cho Việt Nam năm 2016. Sai số giữa kết quả tính toán theo phương pháp chi tiết hóa thống kê tổ hợp trung vị của 11 mô hình khí hậu cho giai đoạn 1986-2005 với số liệu lượng mưa thực đo tại khu vực tỉnh Tây Ninh được trình bày ở Bảng 1.

$(8,9 \%)$. Xu thế ngược lại ghi nhận tại trạm Cần Đăng $(-5,9 \%)$ và Tây Ninh $(-6,5 \%)$. Đối với lượng mưa mùa mưa, kết quả mô phỏng thấp hơn thực đo $\left(\mathrm{RE}_{\text {tinh }}=-7,1 \%\right.$, dao động từ $2 \%$ $15 \%$ giữa các trạm quan trắc), trái ngược với 
lượng mưa mùa khô $\left(\mathrm{RE}_{\text {tỉnh }}=41,2 \%\right.$ - sai số khá cao, dao động từ 32\%-61\% giữa các trạm quan trắc). Những nhận định tương tự được rút ra khi xem xét sai số tuyệt đối MARE: lượng mưa năm với $\mathrm{MARE}_{\text {tinh }}=16,3 \%$ (dao động từ $14-18,7 \%$ ), lượng mưa mùa mưa với $\mathrm{MARE}_{\text {tinh }}=17,6 \%$ (dao động từ 12 - 23\%) và lượng mưa mùa khô với MARE $_{\text {tinh }}=60,4 \%$, sai số cao (dao động từ 59 $65 \%)$.

Trong nghiên cứu này, phương pháp chi tiết hóa thống kê tổ hợp trung vị của 11 mô hình khí hậu có thể được sử dụng để mô phỏng kịch bản biến đổi lượng mưa năm và lượng mưa mùa mưa khu vực tỉnh Tây Ninh với sai số chấp nhận được.

\section{Kết quả và thảo luận}

\subsection{Kịch bản biến đổi lựng mưa năm}

Kịch bản biến đổi lượng mưa tại Tây Ninh đến năm 2100 được trình bày ở Bảng 2 .

Hình 2 cho thấy thấy lượng mưa năm ở Tây Ninh có xu thế tăng theo thời gian (2020-2100) với mức tăng cùng chiều với sự thay đổi các kịch bản KNK (RCP2.6 - RCP8.5). Cụ thể như sau:

- Về giá trị: Đến giữa XXI, mức tăng lượng

Bảng 2. Mức độ biến đổi lượng mura (\%) so với giai đoạn 1986 - 2005 tại tỉnh Tây Ninh

\begin{tabular}{clcccc}
\hline Giai đoạn & Lượng mưa & RCP2.6 & RCP4.5 & RCP6.0 & RCP8.5 \\
\hline \multirow{2}{*}{2020} & Mùa mưa & 4 & 6,3 & 6,7 & 9 \\
& Năm & 5,6 & 7,7 & 8,0 & 8,5 \\
\multirow{2}{*}{2030} & Mùa mưa & 4 & 7,2 & 8,3 & 9,7 \\
& Năm & 5,6 & 9 & 9,3 & 10,9 \\
\multirow{2}{*}{2050} & Mùa mưa & 4,5 & 9,3 & 12 & 15,9 \\
& Năm & 5,8 & 15,6 & 16,0 & 21,1 \\
& Mùa mưa & 7 & 12,5 & 19 & 23,3 \\
& Năm & 7,3 & 18,7 & 21,0 & 24,7 \\
\hline
\end{tabular}

Có thể giải thích hình thái biến đổi lượng mưa theo thời gian và theo các kịch bản RCP bằng sự biến đổi nồng độ KNK trong khí quyển, theo đó là cưỡng bức bức xạ ở các giai đoạn khác nhau đến năm 2100 . Hình 3 cho thấy sự chuyển biến mức độ bắt đầu rõ nét kể từ thập niên 40 của thế mưa năm dao động 5,8 - 21,1\% (RCP2.6 RCP8.5). Số liệu tương ứng vào cuối XXI là 7,3 $-24,7 \%$.

- Xu thế biến đổi giữa các mốc thời gian: có 2 xu hướng (i) mức tăng lượng mưa đáng kể những năm gần giữa thế kỷ (khoảng 7,9\% RCP4.5 - 12,6\% RCP8.5) và tiếp tục tăng giai đoạn nửa cuối thế kỷ XXI (1,5\% RCP2.6 - 2,2\% $\mathrm{RCP} 8.5$ ), (ii) riêng kịch bản $\mathrm{RCP} 2.6$ có mức tăng tương đối tương đồng.

- Chênh lệch giữa các kịch bản RCP: có 2 xu hướng (i) chênh lệch không đáng kể giữa các $\mathrm{KB}$ ở giai đoạn nửa đầu XXI $(5,6 \%$ - 8,5\% năm 2020 và $5,6 \%$ - 10,9\% năm 2030), (ii) chênh lệch khá rõ nét từ năm 2050 đến cuối XXI $(5,8$ - 21,1\% năm 2050 và $7,3-23,63 \%$ năm 2100). Kịch bản RCP 4.5 và RCP6.5 đều thể hiện mức tăng trung bình KNK (lần lượt là trung bình thấp và trung bình cao), nên sai khác kết quả giữa 2 kịch bản này luôn luôn nhỏ ở tất cả các giai đoạn mô phỏng. Xu thế tương tự cũng được ghi nhận trong các kịch bản biến đổi lượng mưa mùa mưa tại tỉnh Tây Ninh đến năm 2100. kỉ XXI. Trong đó, cưỡng bức bức xạ có xu thế tăng liên tục ở kịch bản RCP8.5 (1.350ppm $\mathrm{CO}_{2}$-eq); tăng dần và ổn định đối với kịch bản RCP6.0 (850 ppm CO 2 -eq) và RCP4.5 (650ppm $\mathrm{CO}_{2}$-eq); tăng đến cực đại và giảm dần ở kịch bản RCP2.6 (450 ppm CO $\mathrm{CO}_{2}$-eq). 


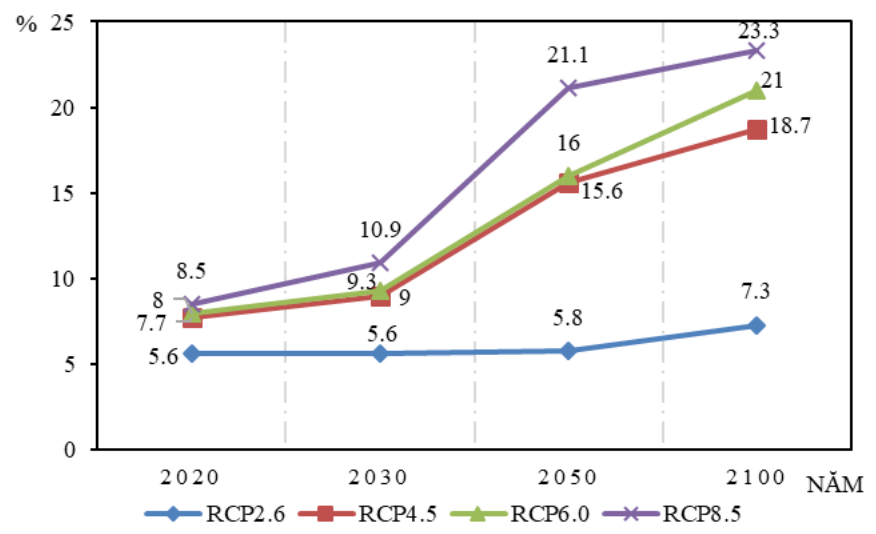

Hình 2. Mức độ biến đổi lự̛ng mưa năm tại tỉnh Tây Ninh so với giai đoạn 1986-2005

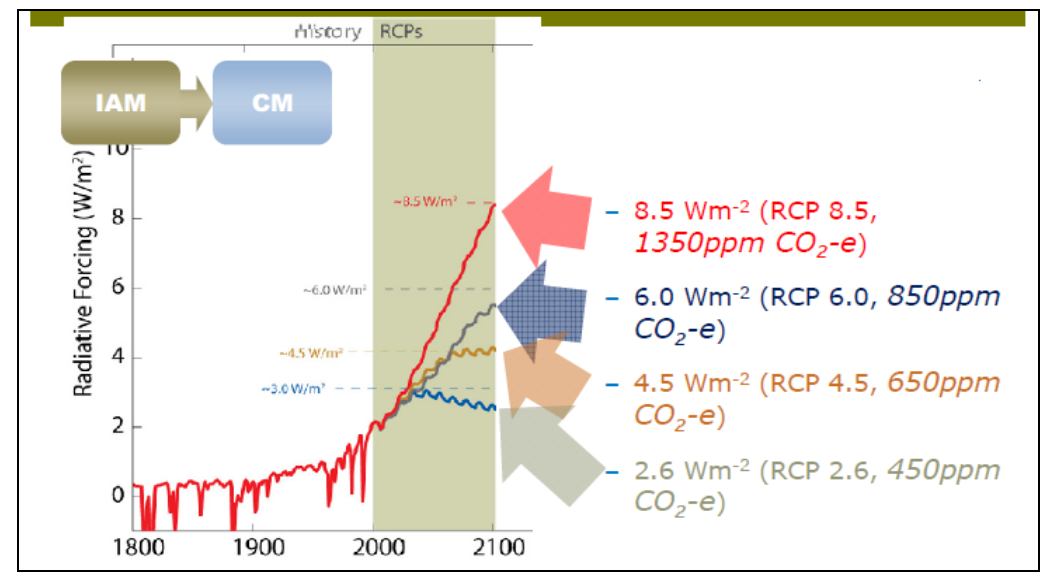

Hình 3. Các kịch bản khí nhà kính sủ dụng trong AR5 [21]

Bảng 2 cũng cho thấy lượng mưa mùa mưa tại tỉnh Tây Ninh gia tăng theo thời gian (2020 2100) và theo các kịch bản KNK (RCP2.6 RCP8.5): mức tăng đến cuối thế kỉ XXI dao động 7\% - 23,3\% (RCP2.6 - RCP8.5) thấp hơn mức độ gia tăng lượng mưa năm $(7,3 \%-24,7 \%)$.

Bảng 3. Phân bố mức độ biến đổi lượng mưa tại tỉnh Tây Ninh so với giai đoạn 1986-2005

\begin{tabular}{|c|c|c|c|c|c|}
\hline \multicolumn{6}{|c|}{ (a) LƯỢNG MU’A NĂM } \\
\hline Kịch bản & Năm & Múc tăng & Xu thế phân bố & Mức tăng cao nhất & Mưc tăng thấp nhất \\
\hline \multirow{3}{*}{$R C P 4.5$} & 2030 & $8-9,5 \%$ & \multirow{2}{*}{$\begin{array}{l}\text { Giảm dần hướng } \\
\text { TN - ĐB }\end{array}$} & Châu Thành & Tân Châu \\
\hline & 2050 & $12-15 \%$ & & Châu Thành, Bến Câu & Tân Châu \\
\hline & 2100 & $18-20 \%$ & $\begin{array}{c}\text { Giảm dần hướng } \\
\text { TB - ĐN }\end{array}$ & Tân Biên, Châu Thành & $\begin{array}{c}\text { D.M. Châu, Trảng Bàng, } \\
\text { Gò Dầu, Bến Cầu }\end{array}$ \\
\hline \multirow{3}{*}{$R C P 8.5$} & 2030 & $9-12 \%$ & $\begin{array}{l}\text { Giảm dân hướng } \\
\text { TN - ĐB }\end{array}$ & $\begin{array}{c}\text { Châu Thành, Bến Câu, } \\
\text { Trảng Bàng }\end{array}$ & Tân Châu \\
\hline & 2050 & $17-22 \%$ & $\begin{array}{l}\text { Giảm dần hướng } \\
\text { Bắc - Nam }\end{array}$ & Tân Châu, Tân Biên & Châu Thành \\
\hline & 2100 & $22-26 \%$ & $\begin{array}{l}\text { Giảm dân hướng } \\
\text { TB - ĐN }\end{array}$ & Tân Biên & $\begin{array}{l}\text { Gò Dâu, Bến Cầu, Trảng } \\
\text { Bàng }\end{array}$ \\
\hline \multicolumn{6}{|c|}{ (b) LỰ̛NG MU'A MÙA MU'A } \\
\hline Kịch bản & Năm & Múc tăng & Xu thế phân bố & Múcc tăng cao nhất & Múc tăng thấp nhất \\
\hline \multirow[b]{2}{*}{$R C P 4.5$} & 2050 & $9-10 \%$ & Giảm từ Tây -Đông & Châu Thành & Trảng Bàng \\
\hline & 2100 & $16-20 \%$ & \multirow{3}{*}{$\begin{array}{c}\text { Giảm dần từ TB - } \\
\text { ĐN }\end{array}$} & Tân Biên, Châu Thành & $\begin{array}{l}\text { Gò Dâu, Bến Câu, Trảng } \\
\text { Bàng }\end{array}$ \\
\hline \multirow{2}{*}{$R C P 8.5$} & 2050 & $13-16 \%$ & & Tân Biên, Châu Thành & Trảng Bàng \\
\hline & 2100 & $21-26 \%$ & & Tân Biên, Tân Châu & Trảng Bàng \\
\hline
\end{tabular}




\section{BÀI BÁO KHOA HỌC}

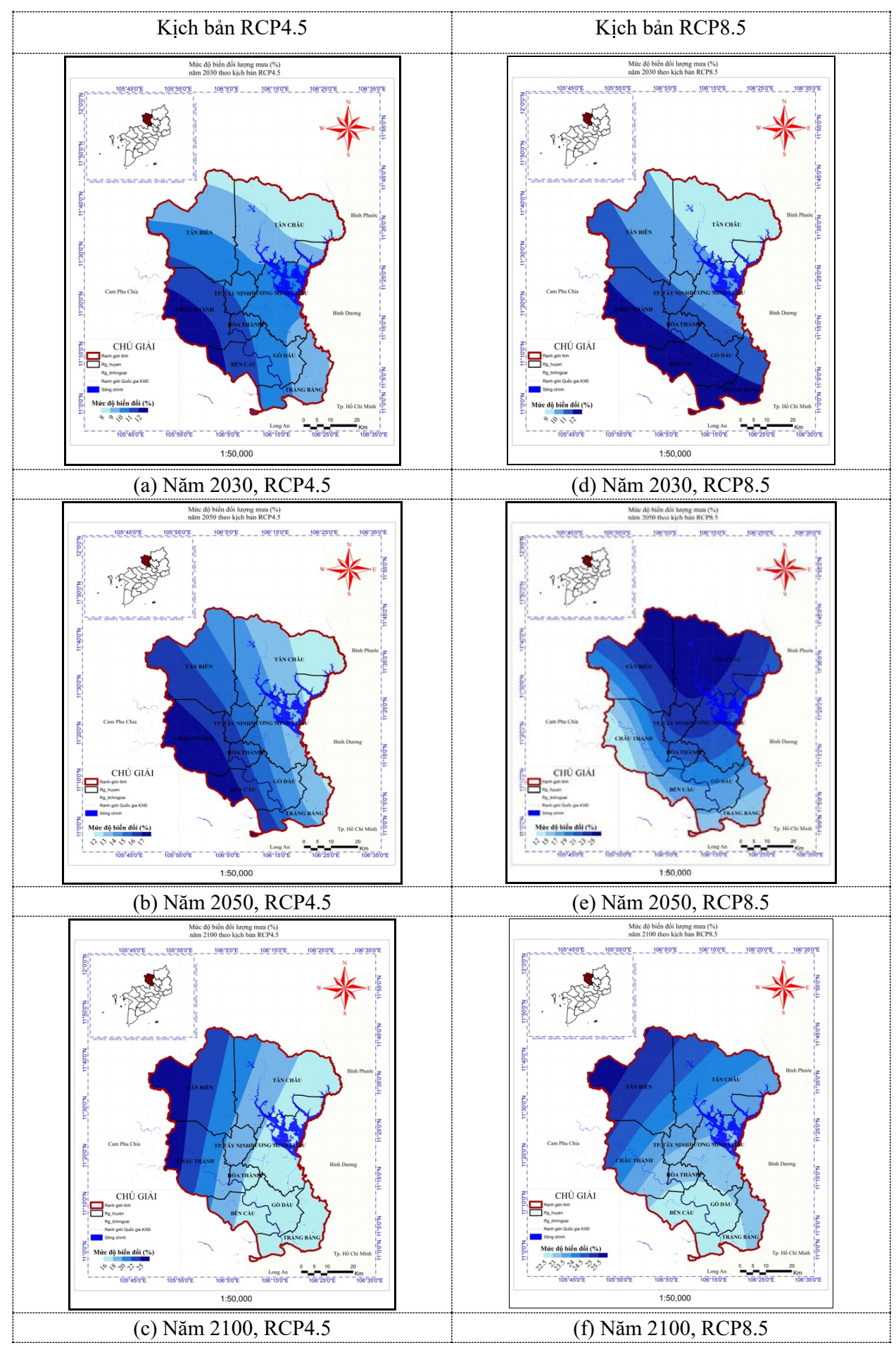

Hình 4. Mức độ biến đổi lượng mura năm tại tỉnh Tây Ninh so với giai đoạn 1986-2005 


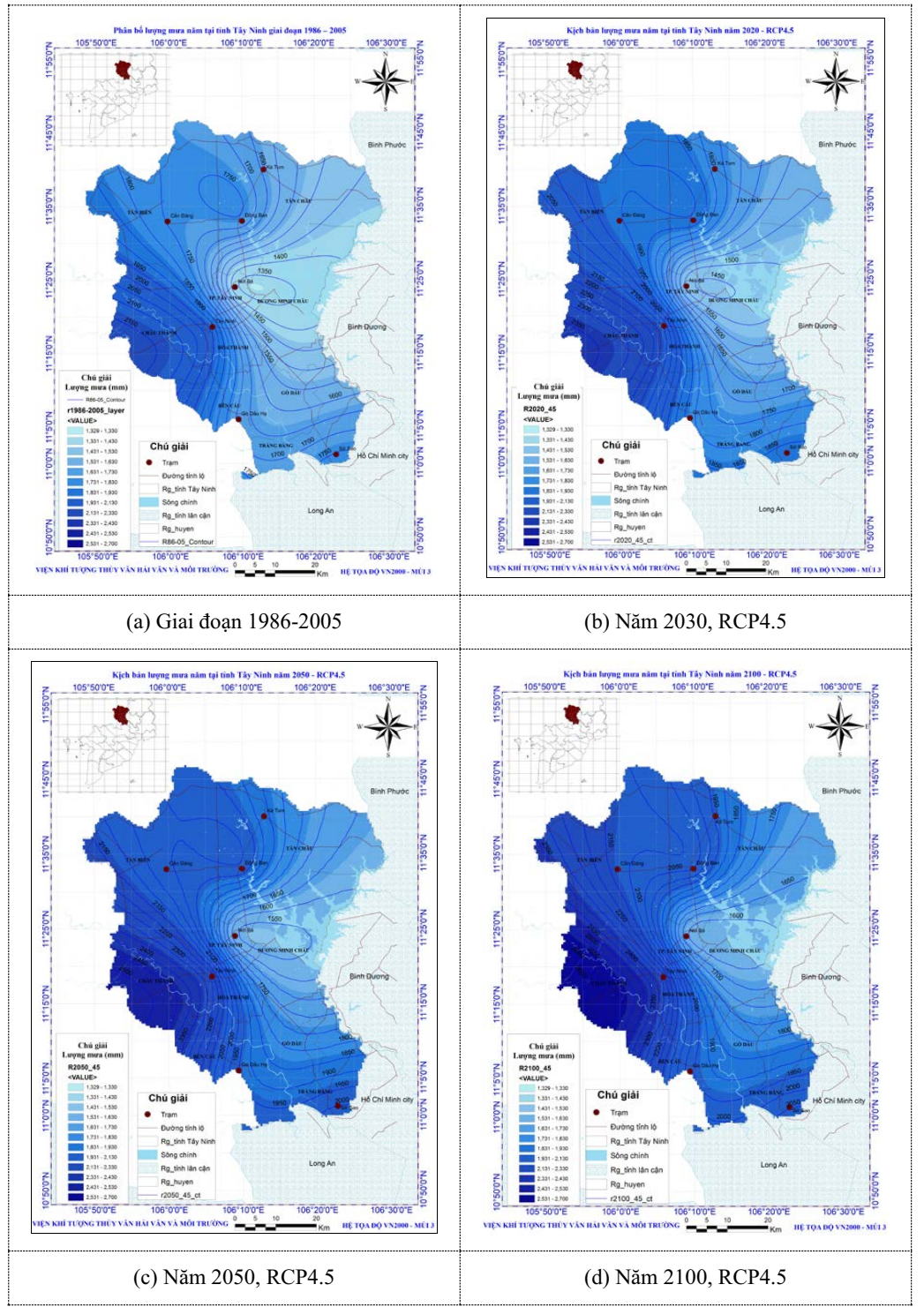

Hình 5. Phân bố lương mura năm tại tỉnh Tây Ninh theo kịch bản RCP4.5

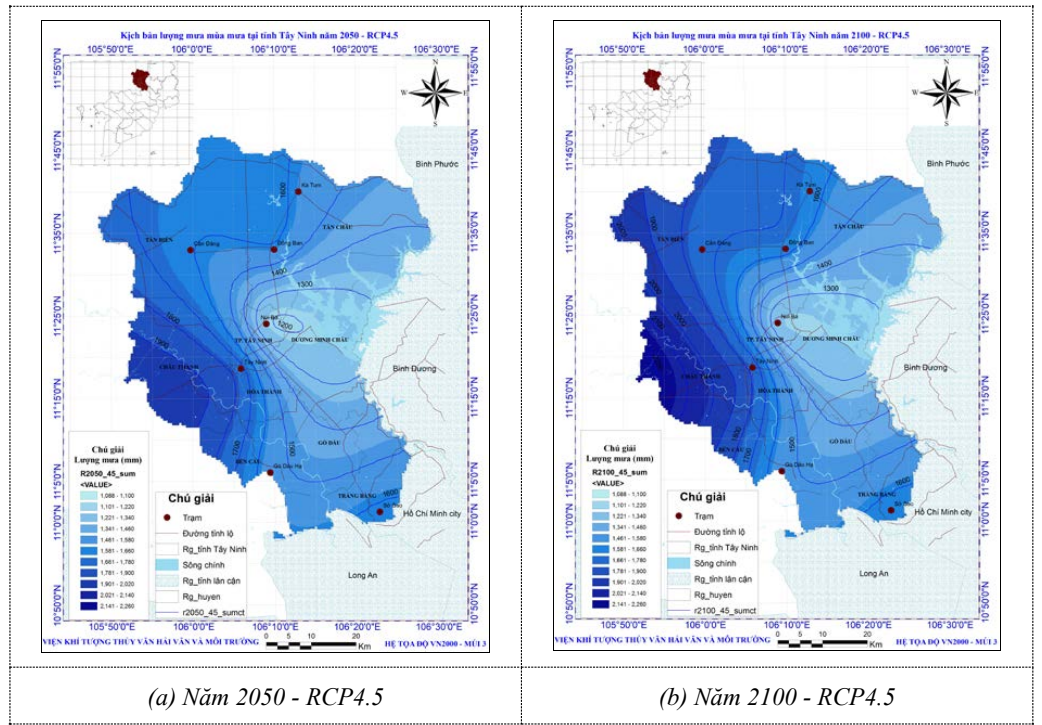

Hình 6. Phân bố lượng mưa mùa mưa tại tỉnh Tây Ninh theo kịch bản RCP4.5 


\section{BÀI BÁO KHOA HỌC}

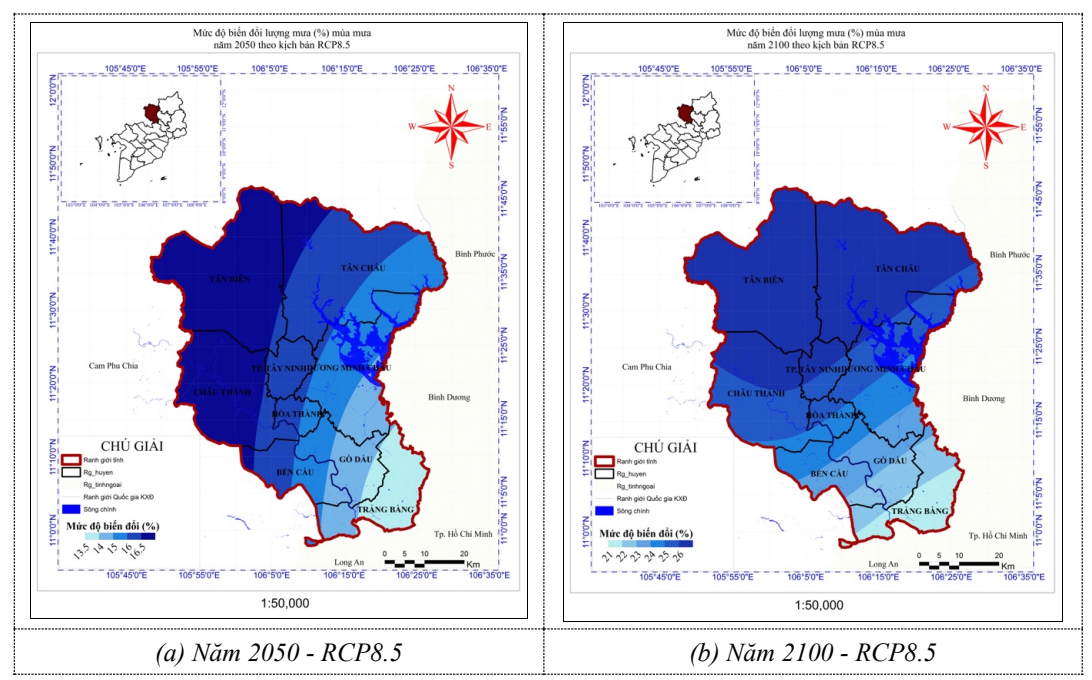

Hình 7. Mức độ biến đổi lượng mưa mùa mưa tỉnh Tây Ninh theo kịch bản RCP8.5

\section{Kết luận}

Bằng phần mềm SimCLIM, nghiên cứu đã xây dựng các kịch bản biến đổi lượng mưa tại tỉnh Tây Ninh đến năm 2100. Theo thời gian cũng như theo các kịch bản RCPs (RCP2.6 RCP8.5), lượng mưa năm ơ Tây Ninh gia tăng $18-20 \% \mathrm{RCP} 4.5$ và $22-26 \% \mathrm{RCP} 8.5$ vào năm 2100 so với giai đoạn 1986-2005. Số liệu tương ứng với lượng mưa mùa mưa là $16-20 \%$ và 21 - 26\%. Theo không gian, lượng mưa (theo năm và theo mùa) ở Tây Ninh phân bố giảm dần theo hướng Tây - Đông. Ở kịch bản RCP4.5, lượng mưa mùa mưa năm 2050 dao động từ 1200-1900 mm, cao nhất ở huyện Châu Thành, Tân Biên (khoảng 1800-1900mm), tiếp sau là Tp. Tây Ninh, Gò Dầu, Trảng Bàng (từ 1500-1600mm), thấp nhất tại huyện Dương Minh Châu (từ 1200$1300 \mathrm{~mm})$. Kết quả nghiên cứu là cơ sở quan trọng cho công tác đánh giá tác động, tính dễ bị tổn thương do sự thay đổi lượng mưa nói riêng và $\mathrm{BĐKH}$ nói chung tại địa phương.

Lời cảm ơn: Nghiên cứu này trong khuôn khổ đề tài NCUD và PTCN cấp tỉnh do Sở KH\&CN tỉnh Tây Ninh là co quan chủ quản và viện KTTV Hải văn và Môi truờng là co quan chủ trì.

\section{Tài liệu tham khảo}

1. Bộ Tài nguyên và Môi trường (2016), Kịch bản Biến đổi khi hậu, nước biển dâng cho Việt Nam, Hà Nội.

2. Phan Văn Tân, Ngô Đức Thành (2013), Biến đổi khi hậu ở Việt Nam: Một số kết quả nghiên cứu, thách thức và co hội trong hội nhập quốc tế. Tạp chí Khoa học ĐHQGHN, Các Khoa học Trái đất và Môi trường, 29 (2), 42-55.

3. Hildebrandsson, H.H., (1897), Quelques recherches sur les entres d'action de l'atmosphère, K. Svenska Vetens - Akad. Handl., 29, 33.

4. Walker, G.T. (1923), Correlation in seasonal variability of weather, VIII. A preliminary study of world weather. Memoirs of the India Meteorological Department, 24, 75-131.

5. Barnston, A.G., Ropelewski, C.F. (1992). Prediction of ENSO episodes using Canonical Correlation Analysis. Journal of Climate, 5, 1316-1345.

6. Tangang, F.T., Hsieh, W.W., Tang, B., (1997), Forecasting the equatorial Pacific sea surface temperatures by neural networks models. Climate Dynamics, 13, 135-147. 
7. Barnston, A.G., Thiao, W., Kumar, V., (1996), Long-lead forecasts of seasonal precipitation in Africa using CCA. Weather Forecasting, 11, 506-520.

8. Ward, M.N., Folland, C.K. (1991). Prediction of seasonal rainfall in the north of Nordeste of Brazil using eigenvectors of sea surface temperature. International Journal of Climatology, 11, 711743.

9. Colman, A.W., (1997), Prediction of summer central England temperature from preceding North Atlantic winter sea surface temperature, International Journal of Climatology, 17, 1285-1300.

10. Phan Văn Tân (2010), Nghiên cứu tác động của biến đổi khi hậu toàn cầu đến các yếu tố và hiện tượng khí hậu cực đoan ở Việt Nam, khả năng dụ báo và giải pháp chiến lược ứng phó, Chương trình KHCN cấp nhà nước KC08/06-10. Mã số đề tài: KC08.29/06-10/

11. Kleeman, R., Moore, A.M., Smith, N.R., (1995), Assimilation of sub-surface thermal data into an intermediate tropical coupled ocean-atmosphere model, Monthly Weather Review, 123, 31033113.

12. Cane, M.A., Zebiak, S.E., Dolan, S.C., (1986), Experimental forecasts of El Nino, Nature, 321, 827-832.

13. Chakraborty, A., Krishnamurti, T.N., (2006). Improved seasonal climate forecasts of the South Asian summer monsoon using a suite of 13 coupled ocean-atmosphere moedels, Monthly Weather Review, 134, 1697-1721.

14. IPCC (2007), Climate Change 2007: Climate Change Impacts, Adaptation and Vulnerability, Summary for Policy Makers, Contribution of Working Group II to the Fourth Assessment Report of the Intergovernmental Panel on Climate Change, Cambridge University Press, Cambridge and New York.

15. UBND tỉnh Tây Ninh (2013), Kế hoạch hành động ứng phó với BĐKH tỉnh Tây Ninh.

16. Bộ Tài nguyên và Môi trường (2009). Kịch bản Biến đổi khi hậu, nước biển dâng cho Việt Nam, Hà Nội.

17. UBND tỉnh Bình Định (2017). Cập nhật Kế hoạch hành động ứng phó với BĐKH tỉnh Bình Định.

18. UBND tỉnh Vĩnh Long (2016). Cập nhật Kế hoạch hành động ưng phó với BĐKH tỉnh Vĩnh Long.

19. Lê Ngọc Tuấn, Ngô Nam Thịnh, Nguyễn Kỳ Phùng (2018), Xây dựng kịch bản mực nuoớc biển dâng trong bối cảnh biến đổi khi hậu cho khu vực thành phố Hồ Chí Minh. Tạp chí Phát triển Khoa học và Công nghệ. Chuyên san KHTN 2 (5), 184-191.

20. Ky Phung Nguyen, Van Tin Nguyen, Ngoc Tuan Le (2017), Precipitation scenarios in Ho Chi Minh city in the context of climate change, Vietnam Journal of Science and Technology, 55 (4C), 115-121.

21. IPCC (2013), Climate Change 2013: The Physical Science Basis. Contribution of Working Group I to the Fifth Assessment Report of the Intergovernmental Panel on Climate Change, Cambridge University Press, Cambridge, United Kingdom and New York, NY, USA, 1535 pp. 


\title{
BÀI BÁO KHOA HỌC
}

\section{PRECIPITATION SCENARIOS IN TAYNINH PROVINCE IN THE CONTEXT OF CLIMATE CHANGE \\ Le Ngoc Tuan ${ }^{*}$, Nguyen Van Tin², Tran Tuan Hoang², Pham Thanh Long', Nguyen Ky Phung ${ }^{3}$ \\ ${ }^{1}$ University of Science - Vietnam National University Hochiminh City \\ ${ }^{2}$ Sub-Institute of HydroMeteorology and Climate change \\ ${ }^{3}$ Department of Science and Technology - Hochiminh City}

\begin{abstract}
By data collecting and processing method and SimCLIM software, this work aimed at developing precipitation scenarios in Tay Ninh province corresponding to RCP2.6, RCP4.5, RCP6.0, and RCP8.5 scenarios. Results showed the annual precipitation would increase over the time and RCPs: 18 -20\% for RCP4.5 and 22 - 26\% for RCP8.5 in 2100 compared to those in the period of 1986-2005. By space, annual and seasonal precipitations in Tay Ninh province would decrease from the West to the East. For RCP4.5, precipitation of rainy season would be 1200-1900 mm in 2050, the highest would distribute in Chau Thanh and Tan Bien districts (1800-1900 mm), followed by Tay Ninh city, Go Dau and Trang Bang districts (1500-1600mm), and the lowest would be at Duong Minh Chau district (1200-1300mm). These results are an important basis for assessing impacts and vulnerability due to precipitation variations in particular and climate change in general in Tay Ninh province.
\end{abstract}

Keywords: Climate change scenario, annual precipitation, seasonal precipitation. 